ISSN: 2146-3042

DOI: $10.25095 /$ mufad.673681

\title{
Borçlanma Maliyetlerinin MSUGT, TMS/TFRS ve BOBİFRS Açısından Muhasebeleştirilmesi*
}

İsmail ELAGÖZ*

Sedef ÖZCAN**

\section{ÖZET}

Ișletmeler, finansman gereksinimlerini özkaynaklara alternatif olarak yabancı kaynak kullanarak da karşılamaktadır. İşletmeler, finansman gereksinimleri ile ilgili yabancı kaynak kullandıklarında faiz, kur farki, vade farkl, dosya masrafi ve komisyon giderleri gibi çeşitli ek maliyetlere katlanmaktadır. İsletmelerin katlandıkları bu maliyetler, borçlanma maliyetlerini oluşturmaktadır. Türkiye'de yabancı kaynak kullanımı sonucunda hangi giderlerin borçlanma maliyeti, hangi giderlerin ise finansman gideri olarak muhasebeleştirileceği ile ilgili Muhasebe Sistemi Uygulama Genel Tebliği, Türkiye Muhasebe Standartları ve Büyük ve Orta Boy Issletmeler İçin Finansal Raporlama Standardı olmak üzere üç ana düzenleme bulunmaktadır. Çalışmanın amacı, Türkiye'de uygulamada olan bu üç farklı düzenleme ile ilgili muhasebe kayttlarındaki farklllıkların örnek uygulamalar kapsamında açıklanmasıdır. Bu amaç çerçevesinde çalışmamızda; işletmelerde bu düzenlemeler doğrultusunda borçlanma maliyetlerinin aktifleştirilmesinin nasıl yapıldığı, bu maliyetlerin aktifleştirilmesinin işletme bilançolarında nasıl gösterildiği ve aktifleştirilme durumları ile ilgili örnek uygulamalara yer verilmiştir.

Anahtar Kelimeler: Borçlanma Maliyetleri, Özellikli Varlı, MSUGT, TMS/TFRS, BOBI FRS

JEL Sinfflandirmast: $M 41$, M48, L15

\section{Accounting of Borrowing Costs In The Context of MSUGT, TMS/TFRS and BOBIFRS}

\section{ABSTRACT}

Businesses meet their financing needs by using foreign resources as an alternative to equity. When businesses use foreign resources related to financing requirements, they incur various additional costs such as interest, foreign exchange difference, maturity difference, file costs and commission expenses. As a result of the use of foreign resources, there are three main regulations in Turkey which are General Communiqué on Accounting System Application, Turkey Accounting Standards and Financial Reporting Standard for Medium and Large Sized Enterprises, on which expenses are to be written as borrowing costs and which expenses are to be written as financing costs. The aim of this study is to describe the differences in accounting records with the scope of practices with those three different regulations being applied in Turkey. For this purpose, examples of how the capitalization of borrowing costs are made in line with these regulations, how the capitalization of these costs are shown in the company's balance sheets and their activation status are given.

Keywords: Borrowing Costs, Qualifying Asset, MSUGT, TMS/TFRS, BOBI FRS

Jel Classification: M41, M48, L15

\footnotetext{
* Makale Gönderim Tarihi: 26.03.2019, Makale Kabul Tarihi: 02.07.201,Makale Türü: Kuramsal Makale

* Dr. Öğr. Üyesi, Çanakkale Onsekiz Mart Üniversitesi, Siyasal Bilgiler Fakültesi, ismailelagoz@comu.edu.tr, Orcid ID: 0000-0003-1856-0746

${ }^{* *}$ Çanakkale Onsekiz Mart Üniversitesi, Sosyal Bilimler Enstitüsü, ozcansedef2@ gmail.com, Orcid ID: 00000002-0537-0962
} 


\section{GİRIŞ}

Küreselleşen ekonomi faaliyetleri ile birlikte çokuluslu işletmeler, finansal raporlarını hazırlarken birçok ülkenin muhasebe uygulamalarını dikkate alarak finansal tablolarını düzenlemek durumunda kalmaktadır. İşletmelerin birçok muhasebe uygulamalarına göre finansal tablo hazırlamaları göz önünde bulundurulduğunda; dünya genelinde muhasebe uygulamalarında ortak standartların kullanılması gerektiği ön plana çıkmışır. Bu konuda uluslararası düzeyde birbiri ile uyumlu muhasebe ve finansal raporlama standartlarının oluşturulması ile ilgili adımlar atılmaya başlanmıştır. Birden fazla ülkede faaliyet gösteren işletmeler, bu muhasebe ve finansal raporlama standartlarına uygun finansal tabloları düzenlemelerinin yanında kendi ülkelerinin muhasebe sistemi uygulamalarına uygun olarak da finansal rapor hazırlamaktadır. Bu durum işletmeler için bir karmaşaya sebep olmaktadır.

Türkiye'deki muhasebe uygulamaları ile ilgili düzenlemeler, genel olarak vergi matrahının tespitini belirlemek amacıyla şekillenmiştir ve bununla ilgili tekdüzeliği sağlamak amacıyla 1994 yılında Maliye Bakanlığı tarafindan Muhasebe Sistemi Uygulama Genel Tebliği (MSUGT) yayımlanmıştır. Bu süreçten sonra Türkiye'de faaliyet gösteren işletmelere bu muhasebe sistemi kapsamında finansal tablolarını düzenleme zorunluluğu getirilmiştir. Ancak küreselleşme ile birlikte ortaya çıan finansal raporlama ile ilgili farklılıklar Türkiye'de de uluslararası alanda uygulanan muhasebe uygulamaları ile ilgili bir düzenleme yapılması gerektiğini ortaya çıkarmıştır. Bununla ilgili olarak Türkiye'de Türkiye Muhasebe Uzmanları Derneği, Türkiye Muhasebe ve Denetim Standartları Kurulu, Türkiye Muhasebe Standartları Kurulu, Sermaye Piyasası Kurulu, Bankacıllk Düzenleme ve Denetleme Kurulu gibi birçok kurum etkin rol oynamış ve standartların temelinin oluşturulmasını sağlamışlardır. 2012 yılında Türk Ticaret Kanunu'nun yenilenmesinden sonra Türkiye Muhasebe Standartları (TMS)'nı ve Türkiye Finansal Raporlama Standartları (TFRS)'nı bağımsız denetime tabi olan işletmelerin uygulaması zorunlu kılınmıştır. Bu düzenlemenin ardından 2014 yılında Kamu Gözetim Kurumu, TMS/TFRS'nin uygulanması ile ilgili zorunluluğu, bağımsız denetim kapsamından ayrıștırarak kamu yararını ilgilendiren kuruluşların uygulaması ile sınırlandırmıştır. MSUGT ve TMS/TFRS'ye ek olarak 2017 yılında denetime tabii olan büyük ve orta ölçekli işletmelerin finansal tablolarını düzenlemeleri ile ilgili olan Büyük ve Orta Boy İşletmeler İçin Finansal Raporlama Standardı (BOBİ FRS) yayımlanmıştır. Yayımlanan bu standart, 1 Ocak 2018 tarihinden itibaren TMS/TFRS kapsamı dışında kalan büyük ve orta ölçekli işletmelerin hazırlamakla yükümlü oldukları finansal tabloları için bir rehber niteliği taşımaktadır.

Türkiye'deki muhasebe uygulamaları ile ilgili standart ve düzenlemeler konusunda yukarıda bahsedilen durumlar göz önünde bulundurulduğunda; MSUGT, TMS/TFRS ve BOBİ FRS olmak üzere üç ana düzenlemenin olduğu görülmektedir. Bu üç ana düzenlemenin aynı anda ülkemizde uygulanması, işletmeler açısından birçok konuda karmaşıklı̆̆a sebep olmaktadır. Bu düzenlemeler içerisinde yer alan konulardan biri de borçlanma maliyetleridir. Borçlanma maliyetleri ile ilgili düzenlemeler MSUGT kapsamında Vergi Usul Kanunu'nda yer alırken TMS/TFRS içerisinde 23 nolu standartta, BOBİ FRS içerisinde ise 17. bölümde yer almaktadır. Bunlar göz önünde bulundurulduğunda çalışmanın amacı; Türkiye'de uygulamada olan bu üç düzenleme ile ilgili muhasebe kaytlarındaki farklılıkların belirlenmesidir. 


\section{BORÇLANMA MALIYETLERİ İLE İLGILLİ DÜZENLEMELER}

Hızla gelişmekte ve globalleşmekte olan dünyada işletmelerin faaliyetlerini ve varlıklarını kesintisiz bir ş̧ekilde sürdürebilmesi, müşteri ihtiyaç ve isteklerini karşılayabilmesi, ulusal ve uluslararası alanda rekabet edebilmesi için finansal kaynaklara gereksinimleri her geçen gün artmaktadır. İşletmeler, finansman gereksinimlerini özkaynakların yanında alternatif bir finansman kaynağı olan yabancı kaynak kullanarak karşılamaktadır. Ayrıca bazı durumlarda işletmeler, finansman politikasına bağlı olarak,, finansal kaldıraç etkisinden yararlanmak istemekte ve özkaynakları yeterli olsa bile, finansman ihtiyaçlarını belli ölçüde yabancı kaynaklardan karşılamaktadır. Yabancı kaynak maliyetlerinin bir kısmının gider yazılabilmesi de yabancı kaynak kullanımını cazip hale getirebilmektedir. İşletmeler, finansman gereksinimlerini karşılamak için veya bahsi geçen diğer avantajlardan dolayı yabancı kaynak kullandıklarında faiz, kur farkı, vade farkı, dosya masrafi ve komisyon giderleri gibi çeşitli maliyetlere katlanmaktadır. İşletmelerin katlandıkları bu maliyetler, durumunda borçlanma maliyetlerini veya finansman giderlerini oluşturmaktadır (Avcı ve Avc1, 2016: 79; Aydın, 2016: 1240; Deran vd., 2016: 13; Küçüktüfekçi ve Kıllı, 2016: 445). Türkiye'de yabancı kaynak kullanımı sonucunda hangi giderlerin borçlanma maliyet, hangi giderlerin ise finansman gideri olarak yazılacağını MSUGT, TMS/TFRS ve BOBİ FRS olmak üzere üç farklı düzenleme bulunmaktadır.

Borçlanma maliyetlerinin muhasebeleştirilmesinin, kar üzerinde oldukça önemli etkisi bulunmaktadır. Çünkü borçlanma maliyetleri doğrudan dönem gideri olarak muhasebeleş̧irildiğinde dönem karını azaltmaktadır. Ayrıca, ilk dönemde karın ortaya çıkması ve işletmenin bu dönem karından vergi ödemesi sonucu işletmenin toplam varlıklarında bir azalma söz konusu olacağını söylemek mümkündür. Bu yüzden borçlanma maliyetlerinin aktifleştirilmesi mali kar ve ticari karın belirlenmesinde büyük önem taşımaktadır (Karataş, 2010: 135; Gönen ve Akça, 2014: 87).

\subsection{Muhasebe Sistemi Uygulama Genel Tebliği Açısından Borçlanma Maliyetleri}

Türkiye'de 1994 yılında yürürlüğe girerek uygulanmaya başlayan Tekdüzen Muhasebe Sistemi (TDMS), genel olarak muhasebe uygulamaları ve değerleme hususunda Vergi Usul Kanunu (VUK)'na bağlı kalmaktadır. Türk mevzuatının temellerinden biri olan VUK'da borçlanma maliyetlerine ilişkin tam bir açıklama yapılmamış ve konuya açıklık getirilmesi bakımından VUK 163 sayılı Tebliğ ve 238 sayılı Tebliğ incelenmiştir. Buna göre vergi mevzuatı açısından borçlanma maliyetleri, maddi duran varlıklar ve stoklar olmak üzere iki açıdan değerlendirilmektedir. 163 sayılı VUK Tebliği'ne göre; kuruluş dönemine ait faiz giderlerinin amortisman yoluyla itfa edilmek üzere maddi duran varlıkların maliyetine eklenmesi zorunlu tutulmuştur. Bir başka ifadeyle duran varlığın aktifleştirildiği hesap dönemi sonuna kadar ödenmesi veya tahakkuk etmesi kesinleşen faiz giderleri, duran varlı̆̆ın maliyetine eklenmek zorundadır. Yatırım aktifleştirildikten sonra ise işletme dönemine ait yatırım ile ilgili faiz giderleri, ilgili bulunulan yılda doğrudan gider yazılabileceği gibi maddi duran varlıkların maliyetine eklenerek amortismana tabi tutulabilmektedir. Buna göre maddi duran varlıklar ile ilgili amortisman ayrılırken; maddi duran varlıkların borçlanma maliyetlerini de içeren elde etme maliyetlerinin esas alınması öngörülmüştür (Çonkar vd., 2007:75). Ayrıca maddi duran varlıklara ilişkin borç taksitlerinin değerlemesinde ortaya çıkacak olan kur farkları için de aynı düzenlemeler söz konusudur. 
Örnek Uygulama: Elit A.Ş. 01.03.2017 tarihinde inşasına başladığ 1 tesisin tamamlanması için 01.10.2017 tarihinde 3 yıl vadeli banka kredisi kullanmıştır. Kullanılan banka kredisinin toplam tutarı 1.000.000 TL olup işletme bu kredi için 2017 yılında 150.000 TL, 2018 yılında 200.000 TL, 2019 y1lında 100.000 TL faiz gideri tahakkuk etmiştir. Binanın inşas 500.000 TL maliyet ile 31.12.2018 tarihinde tamamlanmıştır.

Çözüm: 163 numaralı VUK tebliğine göre bu işlem ile ilgili borçlanma maliyetlerinin kaydı şu şekilde yapılmalıdır:

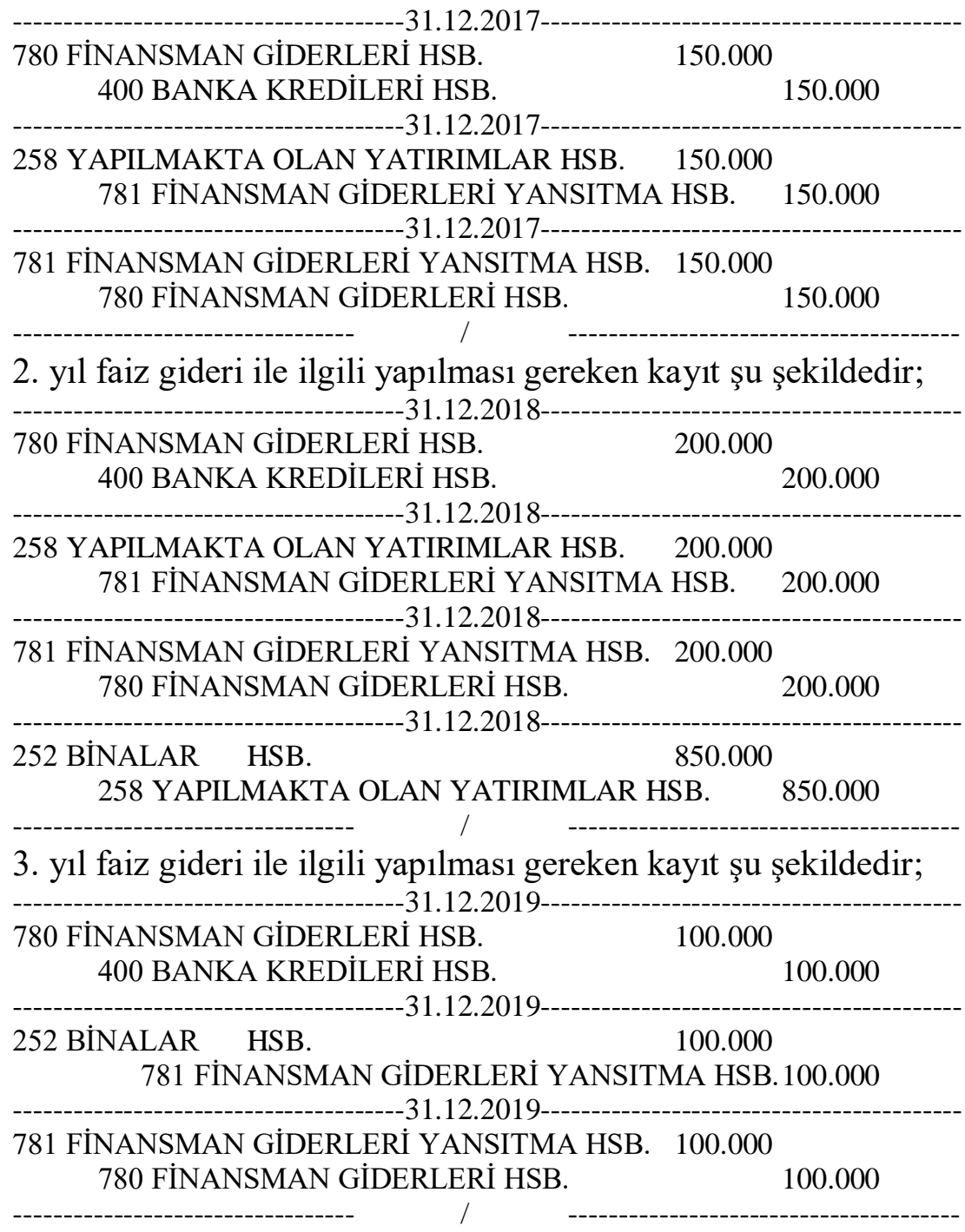

Elit A.Ş.'nin 01.10.2017 tarihinde kullandığı banka kredisi ile ilgili 2017 ve 2018 yıllarında gerçekleşen 150.000 TL ve 200.000 TL tutarındaki faiz giderleri; binanın aktifleştirileceği hesap dönemi sonuna kadar tahakkuk edildiği için faiz giderleri binanın maliyetine eklenmek zorundadır. Binanın 2018 yılı sonunda tamamlanması ile birlikte bina ile ilgili gerçekleşen maliyetler ve faiz giderleri olarak 850.000 TL, "Yapılmakta Olan Yatırımlar" hesabından "Binalar" hesabına aktarılmıştır. Yatırım aktifleştirildikten sonra ise işletme dönemine ait yatırım ile ilgili faiz giderleri, ilgili bulunulan yılda yine binanın maliyetine eklenmiştir. 
Stoklara ilişkin borçlanma maliyetiyle ilgili olan 238 sayılı Tebliğ, borçlanma maliyetine açıklık getirmiş ve VUK 274. maddesi ile satın alınan veya imal edilen emtianın maliyet bedeli ile değerleneceği hükmüne bağlanmıştır. Aynı kanunun 275. maddesinde maliyet bedeline giren unsur olarak borçlanma maliyetinden özel olarak bahsedilmemesine rağmen; bu giderlerin maliyet bedelini veya vergi matrahını etkilemesi yönünde açıklama yapılmıştır. Ayrıca VUK 262. maddesinde, maliyet bedelinin kapsamına ve borçlanma maliyetlerinin ortaya çıkış noktasına değinilmektedir. (Tellioğlu vd., 2013: 320; Çonkar vd., 2007:75). 238 sayılı VUK Tebliği'ne göre; stokların elde edilmesine ve aktifleştirilmesine kadarki süreçte oluşan borçlanma maliyetlerinin, stok maliyetlerinin bir unsuru olarak muhasebeleştirilmesi zorunludur. Buna göre mamulün üretiminde kullanılan ilk madde ve malzeme, mamule isabet eden iş̧̧ilik, genel üretim giderlerinden mamule düşen hisse, ambalaj kullanılmasının zorunlu olduğu durumlarda ambalaj malzemesinin bedeli de zorunlu olarak mamulün maliyetine eklenmektedir. Genel yönetim giderlerinin ise mamulün maliyetine eklenmesi ya da gider olarak kaydedilmesi ihtiyaridir (VUK, Madde 275).

\subsection{Türkiye Muhasebe Standartları Açısından Borçlanma Maliyetleri}

TMS 23 standardında borçlanma maliyetleri; işletmelerin borçlanmalarla ilgili olarak katlandıkları faiz ve diğer giderler olarak tanımlanmaktadır. Buna göre her türlü faiz gideri borçlanma maliyeti ve kur farkları düzeltme ölçüsünde borçlanma maliyeti olarak değerlendirilmektedir (Karataş, 2010: 123). Ayrıca TMS 39 Finansal Araçlar: Muhasebeleştirme ve Ölçme Standardı'na göre etkin faiz oranı kullanılarak hesaplanan faiz gideri, TMS 17 Kiralama İşlemleri Standardı uyarınca finansal tablolara yansıtılan finansal kiralamalara ilişkin borçlanma maliyetleri TMS 23 Standardı kapsamında yer alan borçlanma maliyetleri olarak değerlendirilmektedir. Standartta açıkça tanımlanmamasına rağmen, diğer standartlardan kaynaklanan vadeli alış ve satışlardaki vade ile kur farkları, kıdem tazminatı karşılık giderlerinin hesaplanmasındaki faiz maliyeti ve borçların, alacakların, karşılıkların net şimdiki değerinin hesaplanmasından doğan reeskont giderleri de bu standart kapsamında değerlendirilmektedir (Örten vd., 2018: 561).

Borçlanma maliyetleri ile ilgili olarak standartta özellikli varlık kavramı yer almaktadır. Özellikli varlık, amaçlanan kullanıma veya satışa hazır duruma getirilebilmesi zorunlu olarak uzun bir süreyi gerektiren varlıklar olarak tanımlanmıştır. Ancak, özellikli varlığın tanımında karşılaşılan "uzun süre” kavramı TMS 23’te açıklanmamaktadır. Bu da finansal tabloların karşılaştırılabilirliği ile ilgili sorunların yaşanmasına sebep olmaktadır (Staden ve Merwe, 2012: 96). Ayrica standardin 7. paragrafinda stoklar, imalat tesisleri, enerji üretim tesisleri, maddi olmayan duran varlıklar, yatırım amaçlı gayrimenkuller, taşıyıcı bitkilerden herhangi biri koşullara bağlı olarak özellikli varlık olarak değerlendirilmektedir.

Özellikli varlı̆̆ın elde edilmesi, inşası veya üretimi ile ilgili borçlanma maliyetlerinin varlığın bir parçası olarak aktifleştirilebilmesi için varlık ile borçlanma maliyeti arasında doğrudan bir ilişki olması gerekmektedir. İşletmelerde varlıkla doğrudan ilişsili olmayan diğer borçlanma maliyetleri ise oluştukları dönemde gider olarak muhasebeleştirilmektedir (Yardımcıoğlu ve Kocamaz, 2012: 12). Özellikli varlıkların borçlanma maliyetlerinin aktifleş̧tirilmesi ile kayıtlı değeri değişmekte ve böylece işletmelerin dönem kar/zararında, dönem vergi giderinde ve bilançodaki diğer bazı kalemlerde farklılık söz konusu olmaktadır (Yıldız ve Kurtlar, 2016: 212). İşletme sadece bir özellikli varlığın elde edilmesi için borçlanmışsa, o varlığa ait olan borçlanma maliyetleri kolay bir şekilde saptanabilmekte ve 
özellikli varlı̆ğı maliyetine eklenerek aktifleştirilebilmektedir (TMS 23, Paragraf 10). Borçlanma maliyetlerinin muhasebeleştirilmesinde temel yöntem ve uygulanabilir alternatif yöntem olmak üzere iki ayrı yöntem kullanılabilmektedir. Temel yöntemde; borçlanma maliyetleri (faiz maliyeti, kur farkı gideri, vade farkı gideri, vergi ve fon ile diğer ilişkili maliyetler), gerçekleştikleri borçlanmanın niteliğine ve borçlanma yöntemine bakılmadan dönem gideri olarak muhasebeleștirilmekte ve dönem kar/zarar tablosu ile ilişkilendirilmektedir. Alternatif yöntemde ise özellikli varlığın işletme tarafindan elde edilmesinde, borçlanma maliyetleri ile doğrudan ilişkilendirilebiliyorsa özellikli varlı̆̆ın maliyeti olarak muhasebeleştirilmektedir (Yıldız ve Kurtlar, 2016: 214). Standartta stokların ilgili borçlanma maliyetleri ile ilgili bir sınırlandırma söz konusudur. Bu sınırlandırmaya göre bir işletme stoklarını vadeli ödeme koşuluyla almış ise sözleşmede peşin alım fiyatı ile ödenen fiyat arasında fark söz konusu ise bu fark finanse edildiği dönemde faiz gideri olarak muhasebeleştirilmelidir (Tellioğlu vd., 2013: 321).

Standartta işletmeler, genel amaçlı olarak borçlandığı fonların bir kısmını bir özellikli varlığın finansmanında kullandıklarında ise aktifleştirilebilecek borçlanma maliyeti, aktifleștirme oranı yardımı ile belirlenebilmektedir. Aktifleştirme oranı; özellikli varlık alımı ile ilgili borçlanmalar dışındaki işletmenin ilgili dönemine ilişkin mevcut tüm borçlanma maliyetlerinin ağırlıklı ortalamasının hesaplanması aracıllğıyla tespit edilmektedir. Ancak bir dönem süresince aktifleştirilen borçlanma maliyetleri tutarı, ilgili dönemin borçlanma maliyetleri tutarını aşamaz (TMS 23, Paragraf 14; Karataş, 2010:125).

Örnek Uygulama: Elit A.Ş. 2018 yılında genel finansman ihtiyacı sebebiyle almış olduğu banka kredilerinin tutarları ve faiz oranları şu şekildedir;

\begin{tabular}{|l|r|c|}
\hline \multicolumn{1}{|c|}{ Banka Kredisi } & Tutar & Faiz Oranı \\
\hline X Bankası & 50.000 & $\% 15$ \\
\hline Y Bankası & 200.000 & $\% 5$ \\
\hline Z Bankası & 150.000 & $\% 10$ \\
\hline
\end{tabular}

Elit A.Ş. genel amaçlı kredilerden 60.000 TL'sini özellikli varlık inşasında kullanmıştır.

Çözüm: Buna göre aktifleştirilecek borçlanma maliyetinin hesaplanmasında kullanılacak olan aktifleştirme oranı şu şekilde bulunur;

$$
\begin{aligned}
& {[(50.000 \times \% 15)+(200.000 \times \% 5)+(150.000 \times \% 10)] / 400.000=} \\
& {[7.500+10.000+15.000] / 400.000=} \\
& 32.500 / 400.000=0,081 \\
& \text { Aktifleştirilebilecek tutar }=60.000 \times 0,081=4.860 \mathrm{TL} \text { 'dir. } \\
& \text { 258 YAPILMAKTA OLAN YATIRIMLAR HSB. } 4.860 \\
& \text { 781 FINANSMAN GIDERLERI YANSITMA }
\end{aligned}
$$

Elit A.Ş.'nin 2018 yılında genel finansman ihtiyacı sebebiyle kullanmış olduğu banka kredilerinin ağırlıklı ortalamasının hesaplanması ile aktifleştirme oranı 0,081 olarak tespit 
edilmiştir. Özel varlığın inşası için kullanılan 60.000 TL aktifleştirme oranı ile çarpıldığında dönem içerisinde aktifleştirilecek borçlanma maliyeti tutarı 4.860 TL olarak hesaplanmıştır. Bu tutar özellikli varlığın maliyetine eklendiği için "Yapılmakta Olan Yatırımlar" hesabına yansıtma hesabı aracılığıyla aktarılmıştır.

İşletmeler, borçlanma maliyetlerini özellikli varlığın maliyetinin bir parçası olarak aktifleştirilmesine; varlık için harcama yapılması, borçlanma maliyetlerinin tahakkuk etmesi ve ilgili varlığın amaçlanan kullanıma veya satışa hazır duruma getirilmesi için gerekli faaliyetlere başlanması koşullarının tamamının gerçekleştiği tarihte başlamak zorundadır. Ancak özellikli bir varlığın amaçlanan kullanıma veya satışa hazır duruma getirilmesi için gerekli işlemler; ilgili varlığın fiziksel olarak inşa edilmesi ile sınırlı değildir. İlgili varlığın inşası ile ilgili gerekli izinlerin alınması gibi teknik ve idari faaliyetler de bu işlemler arasında yer almaktadır. Bu tür işlemlerde varlığın durumunu değiştirme söz konusu ise borçlanma maliyetleri aktifleştirilmektedir. Ancak varlığın durumunu değiştiren herhangi bir üretim veya gelişme olmaksızın elde tutulması sırasında oluşan borçlanma maliyetleri aktifleştirilemez. Ayrıca özellikli varlık ile ilgili tahsil edilen hakediş ve devlet teşviki bulunuyorsa, bunlar özellikli varlığa ilişkin harcamalardan düşülmelidir (TMS 2, paragraf 17-18; TMS 23, paragraf 19).

İşletmelerin özellikli varlığın amaçlanan kullanıma veya satışa hazır duruma getirilmesiyle ilgili gerçekleşen faaliyetlerine uzun süreli ara verdikleri dönemlerde oluşan borçlanma maliyetlerinin aktifleştirilmesine de ara vermeleri gerekmektedir. Ancak, ara verilen dönemde önemli teknik ve idari çalışmalar devam ediyorsa işletmeler borçlanma maliyetlerinin aktifleştirilmesine ara vermez. Ayrıca varlığın tamamlanması ile ilgili ortaya çıkan gecikme söz konusu ve bu gecikme varlığın amaçlanan kullanıma veya satışa hazır duruma getirilmesi için gereken işlemlerin vazgeçilmez bir parçası ise borçlanma maliyetlerinin aktifleştirilmesine ara verilmez. (TMS 23: 20-21)

Bir varlığın amaçlanan kullanıma veya satışa hazır duruma getirilmesi için gerekli tüm işlemler tamamlandığında, borçlanma maliyetlerinin aktifleştirilmesine son verilir. Normal şartlar altında, bir varlığın fiziken inşası tamamlandığında, idari işlemler devam etse dahi bu varlığın amaçlanan kullanıma veya satışa hazır hale hazır olduğu anlamına gelmektedir. Bir özellikli varlığın parçalar halinde tamamlanmanın söz konusu olduğu durumlarda tamamlanan parçanın aktifleştirilmesine son verilir, diğer parçalar için aktifleştirme devam eder (Gökçen vd., 2016: 427). Ancak aynı tesis içerisinde birbirine bağlı süreçlerin yer aldığı durumlarda herhangi bir parçanın tamamlanması halinde tamamlanan parça ile ilgili borçlanma maliyetlerinin aktifleştirilmesine son verilmez (TMS 23, Paragraf 25).

Örnek Uygulama: Elit A.Ş. 01.03.2017 tarihinde inşasına başladığ tamamlanması için 01.10.2017 tarihinde 3 yıl vadeli banka kredisi kullanmıştır. Kullanılan banka kredisinin toplam tutarı 1.000.000 TL olup işletme bu kredi için 2017 yılında 150.000 TL, 2018 y1lında 200.000 TL, 2019 y1lında 100.000 TL faiz gideri tahakkuk etmiştir. Binanın inşas 500.000 TL maliyet ile 31.12.2018 tarihinde tamamlanmıştır. 
Çözüm: Borçlanma Maliyetleri ile ilgili standarda göre 1. yıl faiz gideri ile ilgili yapılması gereken kayıt şu şekildedir;

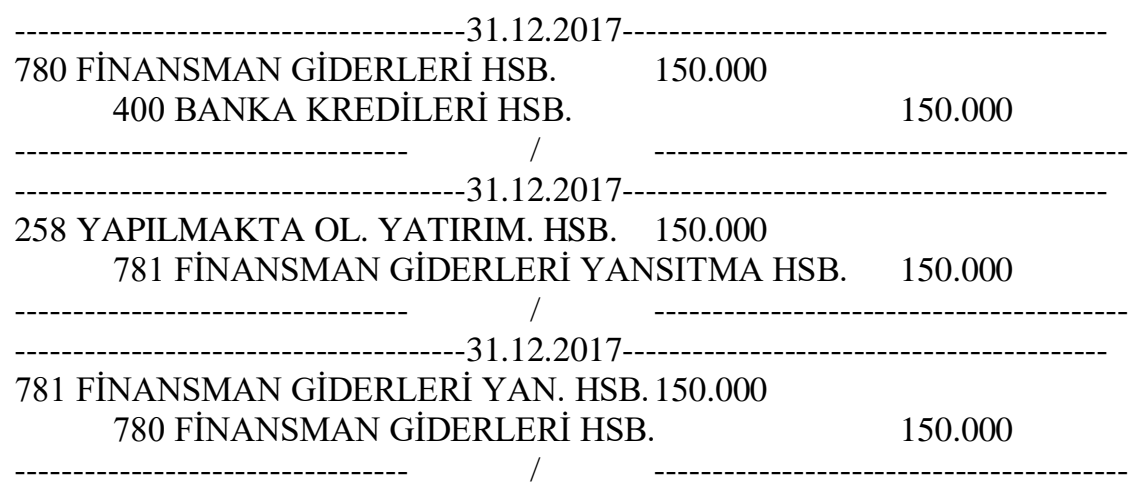

2. yıl faiz gideri ile ilgili yapılması gereken kayıt şu şekildedir;

\begin{tabular}{|c|c|}
\hline $\begin{array}{l}780 \text { FINANSMAN GIDERLERİ HSB. } \\
400 \text { BANKA KREDİLERİ HSB. }\end{array}$ & 200.000 \\
\hline $\begin{array}{l}258 \text { YAPILMAKTA OL. YATIRIM. HSB. } 200.000 \\
781 \text { FINANSMAN GIDERLERI YANSITMA HSB. }\end{array}$ & 200.000 \\
\hline $\begin{array}{l}781 \text { FINANSMAN GIDERLERİ YAN. HSB. } 200.000 \\
780 \text { FINANSMAN GIDERLERİ HSB. }\end{array}$ & 200.000 \\
\hline $\begin{array}{l}252 \text { BİNALAR HSB. } \\
258 \text { YAPILMAKTA OLAN YATIRIMLAR HSB. }\end{array}$ & 850.000 \\
\hline \multicolumn{2}{|c|}{ 3. yıl faiz gideri ile ilgili yapılması gereken kayıt ise şu şekildedir; } \\
\hline $\begin{array}{l}780 \text { FİNANSMAN GIDERLERİ HSB. } \\
400 \text { BANKA KREDILERİ HSB. }\end{array}$ & 100.000 \\
\hline $\begin{array}{l}661 \text { UZUN VADELİ BORÇ. GIDER. HSB. } 100.000 \\
781 \text { FINANSMAN GIDERLERI YANSITMA HSB. }\end{array}$ & 100.000 \\
\hline $\begin{array}{l}781 \text { FİNANSMAN GIDER. YAN. HSB. } \\
780 \text { FINANSMAN GIDERLERİ HSB. }\end{array}$ & 100.000 \\
\hline
\end{tabular}

Elit A.Ş.’nin 01.10.2017 tarihinde kullandığ banka kredisi ile ilgili 2017 ve 2018 yıllarında gerçekleşen 150.000 TL ve 200.000 TL tutarındaki faiz giderleri; binanın aktifleştirileceği hesap dönemi sonuna kadar tahakkuk ettirildiği için faiz gideri binanın maliyetine eklenmek zorundadır. Binanın 2018 yılı sonunda tamamlanması ile birlikte bina ile ilgili gerçekleşen maliyetler ve faiz giderleri olarak 850.000 TL, "Yapılmakta Olan Yatırımlar" hesabından "Binalar" hesabına aktarılmıştır. Yatırım aktifleştirildikten sonra ise işletme dönemine ait yatırım ile ilgili faiz giderleri, ilgili bulunulan yılda dönem gideri olarak muhasebeleştirilerek gelir tablosu hesaplarına aktarılmıştır. 


\subsection{Büyük ve Orta Boy İşletmeler İçin Finansal Raporlama Standardı Açısından Borçlanma Maliyetleri}

BOBİ FRS bağımsız denetime tabi olup TMS/TFRS uygulamayan işletmeler için MSUGT'e ek olarak yerel finansal raporlamaya yönelik eksiklikleri gidermek, finansal tabloların gerçeğe ve ihtiyaca uygun ve karşılaştırılabilir bilgi sunma özelliklerini sağlamak amacıyla yayımlanmıştır (Gökçen vd., 2018: 440). Standart, uluslararası muhasebe ve finansal raporlama uygulamalarına ve $\mathrm{AB}$ düzenlemelerine uygun olarak hazırlanmıştır. Özellikle $A B$ muhasebe direktifindeki "önce küçükleri düşün” yaklaşımına uygun olarak standartta, orta büyüklükteki işletmeler için genel olarak maliyet esaslı bir finansal raporlama öngörülmüş; büyük işletmelere yönelik olarak ise ilâve yükümlülükler getirilmiştir. BOBİ FRS'lerin üzerinde durmuş olduğu en önemli nokta; belirlenen kriterlerle (aktif toplamı, satış hâsılatı ve çalışan sayısı) büyük ve orta ölçekli işletmeleri birbirinden ayırmasıdır. Bağımsız denetime tabi olan işletmeler, tebliğde belirtilen büyük ölçekli işletme eşiğine gelene kadar orta ölçekli İşletmeler olarak; bu eşiği ve üstünü sağlayan (KAYİK dışındaki) işletmeler ise büyük boy işletmeler olarak tanımlanmaktadır (Ataman ve Cavlak, 2017: 156-157).

BOBİ FRS kapsamında yer alan borçlanma maliyetleri ile ilgili düzenleme 17. bölümde yer almaktadır. Bu bölümdeki esaslara göre borçlanma maliyetleri, borçlanmayla ilgili olarak katlanılan faiz ve diğer maliyetlerdir. Ayrıca üretilmesi, inşası ya da oluşturulması normal şartlar altında bir yıldan daha uzun süren stokların, maddi duran varlıkların, yatırım amaçlı gayrimenkullerin ve maddi olmayan duran varlıkların elde edilmesiyle doğrudan ilişkili olan borçlanma maliyetleri (faiz giderleri, kur düzeltme farklılıkları) söz konusu varlığın satı̧a veya kullanıma hazır hale getirildiği tarihe kadar, varlığın maliyetine dâhil edilmektedir. Diğer tüm borçlanma maliyetleri ise oluştukları dönemde kâr veya zarar tablosunun ilgili kaleminde kâr veya zarara yansitılır. İlgili varlık tamamlandıktan sonra ortaya çıkan borçlar ise dönem gideri olarak muhasebeleştirilmelidir (BOBİ FRS, 109).

Örnek Uygulama: Elit A.Ş. 01.03.2017 tarihinde inşasına başladığı tesisin tamamlanması için 01.10.2017 tarihinde 3 yıl vadeli banka kredisi kullanmışıtır. Kullanılan banka kredisinin toplam tutarı 1.000.000 TL olup işletme bu kredi için 2017 yılında 150.000 TL, 2018 yılında 200.000 TL, 2019 yilında 100.000 TL faiz gideri tahakkuk etmiştir. Binanın inşas 500.000 TL maliyet ile 31.12.2018 tarihinde tamamlanmıştır. şekildedir;

Çözüm: Standarda göre 1. yıl faiz gideri ile ilgili yapılması gereken kayıt şu

\begin{tabular}{|c|c|c|}
\hline $\begin{array}{l}780 \text { FINANSMAN GIDERLERİ HSB. } \\
400 \text { BANKA KREDILERI HSB. }\end{array}$ & 150.000 & 150.000 \\
\hline $\begin{array}{l}258 \text { YAPILMAKTA OL. YATIRIM. HSB. } \\
781 \text { FINANSMAN GIDERLERI YAP }\end{array}$ & & 150.000 \\
\hline $\begin{array}{l}781 \text { FINANSMAN GIDERLERİ YAN. HSB } \\
780 \text { FINANSMAN GIDERLERİ HSB }\end{array}$ & 150.000 & 150.000 \\
\hline
\end{tabular}


2. yıl faiz gideri ile ilgili yapılması gereken kayıt şu şekildedir;

\begin{tabular}{|c|c|}
\hline $\begin{array}{l}780 \text { FİNANSMAN GIDERLERİ HSB. } \\
\text { 400 BANKA KREDİLERİ HSB. }\end{array}$ & 200.000 \\
\hline $\begin{array}{l}258 \text { YAPILMAKTA OL. YATIRIM. HSB. } 200.000 \\
781 \text { FINANSMAN GIDERLERİ YANSITMA HSB. }\end{array}$ & 200.000 \\
\hline $\begin{array}{l}781 \text { FINANSMAN GIDERLERI YAN. HSB. } 200.000 \\
780 \text { FINANSMAN GIDERLERİ HSB. }\end{array}$ & 200.000 \\
\hline $\begin{array}{l}252 \text { BİNALAR HSB. } \\
258 \text { YAPILMAKTA OLAN YATIRIMLAR HSB. }\end{array}$ & 850.000 \\
\hline \multicolumn{2}{|c|}{ 3. y1l faiz gideri ile ilgili yapılması gereken kayıt ise şu şekildedir; } \\
\hline $\begin{array}{l}780 \text { FINNANSMAN GIDERLERİ HSB. } \\
\text { 400 BANKA KREDİLERİ HSB. }\end{array}$ & 100.000 \\
\hline $\begin{array}{l}661 \text { UZUN VADELİ BORÇ. GIDER. HSB. } 100.000 \\
781 \text { FİNANSMAN GIDERLERİ YANSITMA HSB. }\end{array}$ & 100.000 \\
\hline $\begin{array}{l}781 \text { FINANSMAN GIDER. YAN. HSB. } \\
780 \text { FINANSMAN GIDERLERİ HSB. }\end{array}$ & 100.000 \\
\hline
\end{tabular}

Elit A.Ş.'nin 01.10.2017 tarihinde kullandığı banka kredisi ile ilgili 2017 ve 2018 yıllarında gerçekleşen 150.000 TL ve 200.000 TL tutarındaki faiz giderleri; binanın aktifleştirileceği hesap dönemi sonuna kadar tahakkuk edildiği için faiz binanın maliyetine eklenmek zorundadır. Binanın 2018 y1lı sonunda tamamlanması ile birlikte bina ile ilgili gerçekleşen maliyetler ve faiz giderleri olarak 850.000 TL, "Yapılmakta Olan Yatırımlar" hesabından "Binalar" hesabına aktarılmıştır. Yatırım aktifleştirildikten sonra ise işletme dönemine ait yatırım ile ilgili faiz giderleri, ilgili bulunulan yılda dönem gideri olarak gelir tablosu hesaplarına aktarılmıştır. Görüldüğü üzere TMS ve BOBİ FRS ile ilgili muhasebe kayıtları birbirinin aynısıdır.

\section{SONUÇ}

Borçlanma maliyetlerinin muhasebeleştirilmesi ile ilgili Türkiye'de MSUGT, TMS/TFRS ve BOBİ FRS kapsamında olmak üzere üç düzenleme yer almaktadır. Türkiye'de uygulamada olan bu üç farklı düzenleme ile ilgili muhasebe kayıtlarındaki farklılıklara örnek uygulamalar kapsamında çalışmada yer verilmiştir. Çalışmada örnek uygulamadan anlaşılacağı gibi, TMS 23 Standardı ve BOBİ FRS kapsamında yer alan borçlanma maliyetlerinin dönem gideri ya da belirli koşulların sağlanması halinde aktifleștirilmesi konularında, MSUGT'de yer alan düzenlemelerden farklılıklar gösterdiği belirlenmiştir. Vergi Usul Kanunu tebliğleri hükümlerinde ve BOBİ FRS kapsamında "özellikli varlık" kavramı yer almaz iken; TMS 23 kapsamında özel varlık kavramı yer almaktadır. Ayrıca 23 numaralı Borçlanma Maliyetleri Standardı'nda özel varlık kavramı ile ilgili bir tanım da yer almaktadır. MSUGT ve TMS/TFRS arasında borçlanma maliyetlerinin belirlenmesi açısından "uzun süre" ile ifade edilen belirsiz yatırım süreci BOBİ FRS ile "bir yılı aşan süre" olarak ifade edilmiştir. Vergi Usul Kanunu tebliğleri hükümlerinde borçlanma maliyetleri, maddi duran 
varlıklar ve stoklar olmak üzere iki açıdan değerlendirilmekte iken; TMS 23'te stoklar, imalat tesisleri, enerji üretim tesisleri, maddi olmayan duran varlıklar, yatırım amaçlı gayrimenkuller, taşıyıcı bitkiler olmak üzere altı açıdan, BOBİ FRS'de stokları, maddi duran varlıkların, yatırım amaçlı gayrimenkullerin ve maddi olmayan duran varlıkların olmak üzere dört açıdan değerlendirilmektedir.

Maddi duran varlıklar ve stoklar açısından MSUGT ile TMS/TFRS ve BOBİ FRS karşılaştırıldığında; üç düzenlemede de maddi duran varlıklara ve stoklara ilişkin yatırımlarda ortaya çıkan borçlanma maliyetlerinin yatırım süresince mutlaka aktifleştirilmesi gerekmektedir. Ancak MSUGT uyarınca, yatırım tamamlandıktan sonra ortaya çıkan borçlanma maliyetlerinin aktifleştirilmesi ya da doğrudan ortaya çıtıkları dönemde gider yazılması hususunda işletmelere serbestlik tanınırken; TMS/TFRS ve BOBİ FRS kapsamında dönem gideri yazılması zorunlu kılınmıştır.

Muhasebenin temel kavramlarından sosyal sorumluluk ve tam açıklama kavramları gereğince işletmeler tarafından sunulan bilgilerin doğru, güvenilir ve açık olması gerekmektedir. Aynı zamanda işletmeler tarafindan sunulan bilgilerin uluslararası alanda tekdüzelik açısından da borçlanma maliyetlerinin muhasebeleştirilmesinde TMS/TFRS'ye ve BOBİ FRS'ye göre hareket edilmesi gerekmektedir. Bu açıdan Maliye Bakanlığı'nın tekdüzeliği sağlamak açısından Vergi Usul Kanunu ve ilgili diğer vergi mevzuatını TMS/TFRS ve BOBİ FRS ile uyumlu olacak şekilde güncellemesi gerekmektedir.

\section{KAYNAKLAR}

Avc1, Anıl - Avc1, Özge Bolaman (2016), "Vade Fark1, Kur Farkı Ve Kredi Faizlerinin Türkiye Muhasebe Standartları ve Vergi Usul Kanunu Kapsamında Değerlendirilmesi”, Mali Çözüm Dergisi, Sayı: 134, 75-90.

Aydın, Sevgi (2016), “TMS 23 ve Vergi Usul Kanunu Kapsamında Borçlanma Maliyetleri”, Süleyman Demirel Üniversitesi İktisadi ve İdari Bilimler Fakültesi Dergisi, Cilt: 21, Sayı: 4, 1239-1249.

Ataman, Başak - Cavlak, Hakan (2017), "Büyük ve Orta Boy İşletmeler İçin Finansal Raporlama Standardı (BOBİ FRS) İle Tam Set Türkiye Muhasebe Ve Türkiye Finansal Raporlama Standartlarının (TMS/TFRS) Karşılaştırılması”, Finans Ekonomi ve Sosyal Araştırmalar Dergisi, Cilt: 2, Sayı: 3, 153-168.

Büyük ve Orta Boy İşletmeler için Finansal Raporlama Standardı (BOBİ FRS), http://www.kgk.gov.tr/ContentAssignmentDetail/1519/BOBI\%CC\%87-FRS-

Uygulam-as\%C4\%B1-Bas\%CC\%A71\%C4\%B1yor, 26.01. 2019.

Çonkar, Kemalettin - Gökçe, Naciye - Tellioğlu, Tülay F. (2007), "TMS 23 Kapsamında Borçlanma Maliyetlerinin Boyutları", Muhasebe ve Finansman Dergisi, Sayı: 36, 71 84.

Deran, Ali - Erduru, İncilay - Sürer, Atilla (2016), "Muhasebe Meslek Mensuplarının TMS 23 Borçlanma Maliyetleri Standardı'na İlişkin Bilgi Düzeylerinin Tespitine Yönelik Bir 
Araştırma”, Erciyes Üniversitesi İktisadi ve İdari Bilimler Fakültesi Dergisi, Sayı: 47, $13-26$.

Doğan, Aziz (2017), "Büyük ve Orta Boy İşletmeler için Finansal Raporlama Standardı ile TMS/TFRS Karşılaştırması”, İşletme Araştırmaları Dergisi, Cilt: 9, Sayı: 4, 770-786.

Gökçen, Gürbüz - Ataman, Başak - Çakıcı, Cemal (2016), "Türkiye Finansal Raporlama Standartları Uygulamaları", İstanbul: Beta Yayınevi.

Gökçen, Gürbüz - Öztürk, Erkan - Güleç, Ömer Faruk (2018), “BOBİ FRS ve TFRS'nin Finansal Raporlara Etkileri Açısından Karşılaştırılması", Finans Ekonomi ve Sosyal Araştırmalar Dergisi, Cilt: 3, Sayı: 2, 437-457.

Gönen, Seçkin - Akça, Neslihan (2014), "Borçlanma Maliyetlerinin Türkiye Muhasebe Standartları ve Vergi Mevzuatı Kapsamında Değerlendirilmesi”, Siyaset, Ekonomi ve Yönetim Araştırmaları Dergisi, Cilt: 2, Sayı: 3, 83-97.

Karataş, Muharrem (2010), "Borçlanma Maliyetlerinin UMS 23, Kobi'ler İçin UFRS ve Vergi Usul Kanunu Kapsamında Değerlendirilmesi”, Mali Çözüm Dergisi, Sayı: 98, 117-144.

Küçüktüfekçi, Murat - Kıll1, Mustafa (2016), "Borçlanma Maliyetlerinin Muhasebeleştirilmesi: TMS 23, Tekdüzen Muhasebe Sistemi ve Vergi Usul Kanunu Çerçevesinde Bir İnceleme”, Uluslararası Yönetim İktisat ve İşletme Dergisi, Özel Say1, 444-460.

Muhasebe Sistemi Uygulama Genel Tebliği, https://www.ismmmo.org.tr/Mevzuat/IV-MaliTablolarin-Duzenlenmesi-ve-Sunulmasi---4000, 25.01. 2019.

Örten, Remzi - Kaval, Hasan - Karapınar, Aydın (2018), "Türkiye Muhasebe - Finansal Raporlama Standartları Uygulama ve Yorumları", Ankara: Gazi Kitabevi.

Staden, L van - Merwe, N van der (2012), "Capitalisation of Borrowing Costs: An Investigation into Technical Uncertainties in IAS 23", South African Journal of Accounting Research, Volume: 26, Number: 1, 95-117.

Tellioğlu, Tülay F - Gökçe, Naciye - Demir, Fatma (2013), "TMS 23-Borçlanma Maliyetlerinin "Yat Üreten Bir İşletme Açısından İncelenmesi”, Süleyman Demirel Üniversitesi İktisadi ve İdari Bilimler Fakültesi Dergisi, Cilt: 18, Sayı: 3, 319-342.

Türkiye $\quad$ Muhasebe Standartları, $\quad 2-\quad$ Stoklar $\quad$ Standard1, http://www.kgk.gov.tr/Portalv2Uploads/files/DynamicContentFiles/T\%C3\%BCrkiye $\% 20$ Muhasebe\%20Standartlar\%C4\%B1/TMSTFRS2016Seti/TMS2.pdf, 10.02. 2019.

Türkiye Muhasebe Standartlar1, 23- Borçlanma Maliyetleri Standard1, http://www.kgk.gov.tr/Portalv2Uploads/files/DynamicContentFiles/T\%C3\%BCrkiye \%20Muhasebe \%20Standartlar\%C4\%B1/TMSTFRS2018Seti/TMS/TMS_23_2018.pdf , 22.01. 2019. 
Vergi Usul Kanunu, http://www.mevzuat.gov.tr/MevzuatMetin/1.4.213.pdf, 26.01. 2019.

Yıldız, Emrah - Kurtlar, Murat (2016), “TMS 23 Borçlanma Maliyetlerinin Aktifleştirilmesi ve Finansal Tablolara Etkisi”, Eurasian Business \& Economics Journal, Say1: 2, 211 220.

Yardımcığlu, Mahmut - Kocamaz, Hilal (2012), "Borçlanma Maliyetlerinin Uluslararası Muhasebe Standartları ve Güncel Ulusal Mevzuatımızdaki Durumu”, Dayanışma Dergisi, Say1: 117, 8-31.

163 Sira No'lu Vergi Usul Kanunu Genel Tebliği (1985). T.C. Resmi Gazete, 18648, 27 Ocak 1985.

238 Sira No'lu Vergi Usul Kanunu Genel Tebliği (1995). T.C. Resmi Gazete, 22218, 2 Mart 1995. 
